\title{
Learning from Success: How Original Research on Academic Resilience Informs what College Faculty Can do to Increase the Retention of Low Socioeconomic Status Students
}

\author{
Erik E. Morales ${ }^{1}, \mathrm{PhD}$ \\ ${ }^{1}$ Professor, College of Education, New Jersey City University, Jersey City, NJ, USA \\ Correspondence: Erik E. Morales, PhD, College of Education, New Jersey City University, Jersey City, NJ, USA. \\ E-mail: emorales2@njcu.edu
}

Received: June 8, 2014

doi:10.5430/ijhe.v3n3p92
Accepted: July 14, $2014 \quad$ Online Published: July 16, 2014

URL: http://dx.doi.org/10.5430/ijhe.v3n3p92

\begin{abstract}
Utilizing resilience theory and original research conducted on fifty academically resilient low socioeconomic status students of color, this article presents specific objectives and values institutions of higher learning can adopt and emphasize to increase the retention and graduation of their most statistically at-risk students. Major findings and suggestions include: constantly build students' self-efficacy; help students realistically appraise their own strengths and weaknesses; encourage help seeking tendencies; and provide clear linkages between academic success and future economic security.
\end{abstract}

According to a recent report from National Center for Education Statistics, by the year 2022, White and Asian students will increase their attendance on college campuses by $7 \%$, whereas the rate will be $26 \%$ for African American students and $27 \%$ for Hispanics, two groups with disproportionately higher poverty rates (Hussar \& Bailey, 2014). These students will continue to make up larger and larger percentages of students on college campuses nationwide. While these can be viewed as positive and exciting forecasts, they bring with them new sets of challenges.

Given the changing racial, ethnic, and socioeconomic demographics of the United States, as well as shifts in expectations as to who seeks a college degree, a majority of institutions of higher education are struggling with one essential question: How do we retain and graduate greater numbers of ethnic minorities and students from lower socioeconomic backgrounds? The consequences of not meeting this challenge can be viewed on both a macro and micro level. From a societal perspective, unemployment rates, reliance on public social service agencies, incarceration rates, and America's place in the global hierarchy are all either directly or indirectly linked with the successful education of working class and poor students, many of whom are ethnic minorities. On a more local level, as more and more first generation college students enter colleges across the country (Jehangir, 2010), institutions are increasingly recognizing the value of effectively meeting their needs (Bastedo \& Gumport, 2003), for if they don't, current and future enrollment targets may not be met. Furthermore, those with the most influence over the potential success of these students, college faculty, already acknowledge the need for, and desire, effective ways of meeting their needs (Erisman \& Looney 2007).

The difficulties colleges face in effectively teaching and graduating lower socioeconomic status students, often from ethnic minority backgrounds, continues to be a pressing issue. However, the issue is not a new one. Back in the early 1970s K. Patricia Cross (1971) famously talked specifically of the inability of colleges to adjust to the needs of the changing student bodies of the time. Since then, the numbers of poorer and first generation college students have only increased. Furthermore, many noted researchers in the field still acknowledge that not enough is known about how low socioeconomic college students experience and manage college life (Pascarella, Pierson, Wolniak, \& Terenzini, 2004; Pike \& Kuh, 2005).

The rest of this paper will further define and explore the parameters of these issues and then utilize original research on academically resilient students to provide specific approaches faculty can adopt to increase the degree of resilience and persistence among first generation college students. These suggestions will be categorized and explained, then justified through related research literature.

Keywords: Academic resilience, Student retention, At-risk students, Minority student performance 


\section{The Problem}

Currently, only a little more than half (56\%) of students beginning college any given fall will earn their degrees within six years, and these percentages are even lower for African Americans and Hispanics, 39\% and 49\% respectively (NCES, 2013). There are similar variations in college graduation based on socioeconomic status, with poorer students consistently graduating at lower rates than their wealthier peers (Fox, Connolly \& Snyder, 2005).

Perhaps even more troubling, even for students of similar academic ability, those from poorer economic backgrounds still suffer significantly lower graduation rates that their equally academically talented peers. For example, in a longitudinal study, poor students who scored high on an eighth grade mathematics assessment graduated college at a $29 \%$ clip, whereas students with similar math scores from middle income families were at $47 \%$, and high income families at $74 \%$ (Fox et al., 2005). There are questions and debates as to exactly why poor and ethnic minority students continue to graduate college at lower rates, but what virtually everyone agrees on is that colleges and universities can and should do more to address the issue.

The goal of increasing retention rates for ethnic minority students, especially those from the lower rungs of the socioeconomic latter, has remained a major concern for institutions of higher learning throughout the United States (Hill \& Woodward, 2013; O'Keeffe, 2013; Seidman, 2007). Furthermore, the fact that, despite national economic highs and lows, the earning of a college degree is still the most direct route to escaping poverty (Perna, 2005), means it is imperative that we continue to pursue ways of increasing college graduation, particularly for our poorest and most vulnerable students.

There has been a good amount of research exploring and documenting student adjustment to college life and retention (Astin 1993; Hausmann, Schofield, \& Woods, 2007; Pascarella \& Terenzini 2005; Tinto 1993), as well as research specifically focused on low socioeconomic students and their transitions to college (Kraemer, 1997; Morales, 2012; Terenzini, 1994). The bulk of these studies relied on quantitative regression analysis to isolate which variables correlated with eventual graduation (see Bai \& Pan, 2010, for an extant example). These works have often successfully met their goals. However, there has not been as much work done on specifically how poor students have managed to excel despite stressors which often derail others with similar backgrounds. This is where resilience theory and research can play a major role.

\section{Resilience Theory}

Essentially, educational resilience is the statistically anomalous academic achievement of students who possess and confront "risk factors" that predict failure for most students from similar circumstances (Morales \& Trotman, 2004). These students were appropriately termed by Gerardi (1990) as the "the statistical elite" (p. 403). Unlike many other perspectives on the academic performance of poor students, resilience theory takes an up close and personal look at those students who have succeeded, and then asks why and how?

By applying a resilience paradigm, colleges and universities can attempt to enhance and replicate the attributes and conditions that successful poor students have identified as critical to their success. Another benefit of resilience theory is that, because it looks at success over time, the longer term benefits of particular attributes and conditions can be assessed. Finally, the resilience model allows for a sense of how multiple protective factors can work collectively, supplementing each other as they contribute to the success of the student. See Morales (2010), for detailed analysis of how protective factor "clusters" facilitate resilience.

Initially, the resilience concept was applied to positive mental health outcomes despite psychological stressors (Garmenzy, 1991; Rutter, 1979; Werner \& Smith, 1982), rather than educational outcomes. However, it gradually evolved as lens through which unlikely academic success could be viewed as well (Wang \& Gordan, 1994).

In conceptualizing "resilience" there has been debate as to whether it should be viewed as an outcome or a process (McCubbin, 2001). For the sake of this research, the term "resilience" is a broad umbrella concept, capturing both the outcome and process of exceptional academic achievement despite the presence of potentially virulent risk factors.

Though academic resilience as a field of study has recently become more prominent in the social science literature (Conchas, 2006; Hartley, 2013; Hawkins, \& Mulkey, 2005; Kitano \& Lewis, 2005, this focus on positive outcomes remains minuscule compared to all of the work still being done on student failure (Morales \& Trotman, 2011). This is where resilience studies and theory distinguish themselves and can contribute to a better understanding of the whole picture when it comes to the academic performance of poor and ethnic minority students. Despite the daunting statistics discussed earlier, the fact remains that a percentage of students do beat the odds and exceed expectations. Resilience theory is based on the reasoning that if we learn how at-risk students succeed, we can better 
help those with the potential to succeed. Consequently, a brief overview of the resilience paradigm and theoretical construct would be helpful.

Kitano and Lewis (2005) articulated the four dynamics most often utilized in resilience theory: risk factors, protective factors, vulnerability areas, and compensatory strategies. Risk factors refer to any (usually environmental) dynamics which serve to, or have the potential to, negatively impact an individual on his/her path toward academic success. As examples, these may include inferior schools, lack of access to technology, or insufficient funds for test preparation or quality textbooks. To some extent these are always present, because by definition, resilient students face significant risk factors on their journeys toward educational achievement. Protective factors on the other hand serve to offset or mitigate the risk factors and come in a variety of forms as well. Examples are caring teachers, mentors, quality schools, and inspiring parents/role models.

A vulnerability area is a particular issue that manifests as problematic in given situation. For example, while a risk factor may be lack of access to honors courses, the resulting deficiency in that student's college application would be the vulnerability area. Compensatory strategies are protective factors in action, specific actions that alleviate or even defeat risk factors and vulnerability areas. An effective letter of reference to a college admissions office documenting all of the obstacles the student has overcome would be an example.

It is through a resilience lens, and based on original research, that specific protective factors and compensatory strategies will be presented. These are suggestions, attitudes, and values that colleges in general, and faculty in particular, can adopt to increase the degree to which they create an environment conducive to resilience.

There are myriad ways to increase retention, and many of them are being attempted at colleges across the country. There are scholarships to offset the need to work, summer bridge programs, freshmen seminars, student affairs programming, mentoring groups, learning communities, comprehensive tutoring, and supplemental instruction initiatives, just to name a few. Many of these approaches work and should be continued, however they usually exist outside of where students are spending the vast majority of their formal learning time, the classroom.

What often gets far less attention than it should is what faculty can do in their classrooms, on a daily, weekly, and semester basis, to increase retention and promote academic resilience.

\section{Method}

The tenets and suggestions proposed below are based upon original research conducted on fifty ethnic minority academically resilient students. A sample population of 50 is usually high for a primarily qualitative study, and yielded a rich and robust array of findings.

Students were recruited from a variety of institutions: private universities $(n=26)$, public universities $(n=16)$, and community colleges $(n=8)$ and all met the following prerequisites at the time of the interviews:

- Had parents with limited educational backgrounds (HS graduates or below)

- Self-identified as an ethnic minority.

- Had completed a minimum of 30 college credits with a minimum grade point average of 3.0 (using a 4.0 point scale).

Based on ubiquitous data indicating that ethnic minority students from poor backgrounds are statistically less likely to attend and succeed in college (US Dept. of Education, 2013), all students who meet the above criteria can be deemed "academically resilient." That is, their academic performance far exceeded what would have been predicted given their statistical starting points.

Thirty-one of the students were female and nineteen were male. Twenty one identified as African American, twenty as Hispanic/Latino, five as Biracial, two as Haitian American, one as Jamaican American, and one as Guyanese American.

In undertaking the research, ultimate goals were accuracy, completeness and data saturation. Completeness is the principle of adding interviews until one is satisfied with the level of understanding for the given phenomenon (Rubin \& Rubin, 1995). The saturation point is when additional interviews add little to what has already been learned (Ely, 1991; Glaser \& Strauss, 1965). Through fulfillment of both completeness and data saturation, the researcher is confident that the findings present are accurate.

In accordance with the work of Rubin and Rubin (1995) topical semi-structured interviews were conducted. The topic was the students' academic resilience and their mental states throughout that process, and structure was provided by an interview protocol used for all students during their initial interviews. Consequently, while all 
students were asked the same initial questions, follow-up interviews were somewhat unique and based on specific interviewee responses from the previous rounds.

Each interviewee underwent a minimum of three separate interviews. Each interview was approximately ninety minutes in length. The first two interviews primarily gathered data and explored broad themes related to the students' academic resilience, while subsequent interviews were highly focused member checks on specific areas of importance and concern. Each interview was recorded and later transcribed verbatim. During and after each interview supplementary notes were recorded. These notes were an attempt to capture the researcher's own thoughts, as well as nuances not evident in an audio recording,

In conducting this research data collection and analysis were distinct processes that were closely intertwined. Consistent with the qualitative research norms (Lincoln \& Guba, 1985; Rubin \& Rubin, 1995) these two activities were done continuously until data saturation was achieved. Throughout the actual data analysis process, and in accordance with the work of Bogdan \& Biklen (1982) coding categories and concepts were created, and emerging themes identified.

All interview transcriptions became part of the field log. Ely (1991) describes the log as a cohesive history of the investigation. Additional components of the log include the supplementary field notes previously mentioned, and personal reflections and descriptions. These writings were then used to write lengthier writings called analytic memos (Bogdan \& Biklen, 1982). The analytic memos allowed for the ultimate synthesis of all the components of field $\log$.

Finally, trustworthiness was a key objective during the research process. For the qualitative researcher, trustworthiness refers to assurance that the research activities are instituted fairly, and that the conclusions yielded from the research represent as closely as possible the experiences of the people being studied (Ely, 1991). A variety of methods were used to promote trustworthiness, including: triangulation, coherence of themes, peer de-briefing, and member checking. It is the belief and hope of the researcher that what is presented here is as accurate and precise as is reasonably possible.

\section{Research Question}

The findings from the above research were brought to bear on the following question:

- What can faculty do in their classrooms to facilitate the resilience and retention of low socio-economic students?

The presentation of strategies and suggestions, like those that follow, are essential given that most college faculty have never received training on how to teach, let alone how to teach students from varied economic and ethnic backgrounds. Unlike the certification required for k-12 teachers, there is none for college faculty. They are hired based on their expertise in their academic discipline, and then expected to excel at teaching, with little or no professional development or support. Given this reality, it is no wonder many are confounded and dismayed when their students continually struggle despite sincere efforts by both parties

\section{Findings}

The findings below describe some of the specific ways that higher education institutions encouraged the resilience of the students in the study, and ways that other institutions can also accomplish this goal. More important than the specific means, the broader categories are what colleges and universities should be targeting. Different institutions have different cultures, missions, and student bodies, consequently how various institutions adopt and implement the strategies below may differ as well.

The broad categories of suggestions that follow are: Constantly Build Students' Self-Efficacy; Help Students Realistically Appraise their Own Strengths and Weaknesses; Encourage Help-Seeking Tendencies; and Provide Clear Linkages between Academic Success and Future Economic Security. A detailed look at each, with select research support where appropriate, follows.

\section{Constantly Build Students' Self-efficacy}

Strong feelings of self-efficacy (Bandura, 1977), closely related to the concept of an internal locus of control (Rotter, 1966), is perhaps the most commonly cited attribute of academically resilient students (Morales \& Trotman, 2011). Students' beliefs in their ability to effect outcomes is paramount. Increased senses of self-efficacy and an internal locus of control lead to more effort expended on academic tasks, while a lack of self-efficacy (an external locus of control) tends to reduce the amount of effort expended. 
Self-efficacy was among the most commonly cited valuable dispositional attributes of the students studied. A full $92 \%$ of the students studied identified the belief in their own ability to affect change as a key component of their success. While this is not a particularly unique finding, the question of how to encourage and build self-efficacy in others is an ongoing and elusive challenge.

According to the seminal work of Bandura (1977) self-efficacy derives from four primary sources of information:Performance accomplishment (having been successful in the past), Vicarious experience (hearing about others who have been successful), Verbal persuasion (encouragement), and Physiological states (emotional arousal). The first two, performance accomplishment and vicarious experience, appear to have been the most useful and efficacious means to self-efficacy for the students studied. Consequently, some specific strategies college faculty can engage in to bolster self-efficacy follow:

- In designing their syllabi, faculty can begin their semester with relatively straightforward and clear assignments that lend themselves to direct correlation between effort and outcome. In other words, assignments that are relatively simple, as long as ample effort is expended.

Students in the study noted that early success in their classes, as well as a correlation between their efforts and that success, reinforced their confidence and increased the degree to which they believed effort would be rewarded. Examples of assignments that appeared to meet these criteria include: identifying and summarizing relevant newspaper articles, defining lists of vocabulary words germane to a particular academic discipline, and reading a text passage and answering comprehension questions. Note that these assignments do not require a lot of additional outside knowledge or resources, nor abstract thinking, but rather are heavily effort based. This does not mean students should never engage in critical/abstract thinking, but rather that early assignments that minimize the need for these appeared to build an authentic sense of confidence in relation to the particular course. Once students believed their efforts were being rewarded, they put forth more energy on future, more challenging tasks.

- While addressing students, faculty can talk about and promote previous students who have worked hard and succeeded, as well as how these students managed to do so.

Students in the study benefitted from professors who "demystified" what it takes to succeed in their courses by describing students who may have initially struggled, but ultimately succeeded. In addition to acquiring specific insights into what it takes to succeed, the possibility of success became more realistic. Specific suggestions of what to do also helped students guide their energies in fruitful directions. As one student reported:

A lot of times I want to work hard, I really do, but I'm not sure what to do. Like I will spend a bunch of time reading a chapter, and I'll barely remember it, or I remember the wrong stuff when the test comes....Professor (O'Leary) helped because she told me exactly what I needed to do to do good in her class, she told us that the only stuff we needed to know from the book was stuff that she covered in class and that we didn't have to spend time on any of the stuff from the book she didn't also cover. So I would take really good notes and then compare to the book and study just that stuff... I got my first A in that class after she said that, and I kept on doing it. It felt great to know what to do and then to just do it." (Lamar).

Here we see that for students who do not have, nor have access to, "insider" academic knowledge, simple instructions and directions can make all the difference

- Building on the notions above, professors who described their own struggles with, and ultimate mastery of, their academic disciplines were particularly impactful.

These professors humbled themselves, essentially closing the social/intellectual distance between them and their students. The result was described by one student in the following way, "When Professor (Smith) talked about failing out of his first college when he was nineteen, it really made me think about how people can take detours in life and stuff, and still get where they want to be...he made it clear that just because you mess up (it) doesn't mean that's the end of the game...I can still do it" (Angel). Ultimately, these expressions of humility and hardship can help students buy into the possibilities of their own successes. This can be particularly valuable for first generation college students who often view academia as a strange and foreign land, a place in which, deep down inside, they may not feel they belong.

- Another commonly reported characteristics of professors who helped encourage self-efficacy in their students is that they provided frequent, specific, and detailed feedback on as many assignments as possible, especially early in the semester.

Often students increased their effort output, as well as their belief in the value of that output, in response to knowing specifically when they either excelled or missed the mark. Consistent feedback helped students link effort with outcome and guided them on what to do next. As discussed earlier, a common, and frustrating, conundrum for many 
potentially resilient students is that they are ready and willing to work hard, but are not knowledgeable and/or academically sophisticated enough to know exactly what to do. Consistent and detailed feedback helps solve this problem. One student's words typified many of the resilient students' grateful reactions to these sorts of criticism, "it (the detailed feedback) was like a map, it kept me on track and let me know that I was making progress, like that what I was doing was working, or that I needed to change, that's valuable information. In some of my other classes, I had like no clue where I was, I was kind of lost, and it made me not want to work as hard." (Lucy).

- Another faculty approach which appeared to bolster self-efficacy was the provision of choice when it came to course assignments.

Many students expressed a sense of empowerment when they worked on an assignment or topic that they chose. For many of the students, choice often led to ownership, which encouraged effort and responsibility. A student's discussion of a poetry professor who allowed her to use rap music lyrics in her final analysis paper exemplifies this well:

At first I was shocked that she even let me do it, and I thought it would be kind of easy. But it wasn't. Yeah, she let me do it, but I still had to analyze it the same way as with any of the poems, she wanted us to dig deep and make connections with other stuff.... I didn't mind doing the work because I chose it, it was mine... I worked harder on that paper than on anything I have ever done in school, and I'm also most proud of it. (Deborah)

- Another way faculty enhanced self-efficacy was by emphasizing the developmental and nonlinear nature of academic competence and achievement. These faculty helped students learn by their "failures" by stressing learning as a growth process rather than an either you have it or you don't construct.

Although they did not use these terms, essentially the students were benefitting from professors who viewed academic competence with what researcher Carol Dweck refers as a "growth mindset" (2006). In her research, Dweck found that students who are told they excel because of innate intelligence (a fixed entity) do not do as well and are not as academically courageous as those who are told they excel because of effort (a malleable, incremental "growth" mindset"). This ties directly to self-efficacy, for theoretically while one does not control a "fixed entity" one can control effort and gradual growth, two pillars of self-efficacy.

\section{Help Students Realistically Appraise their own Strengths and Weaknesses}

A difficult, though essential, step in the process of becoming resilient is developing one's ability to not only engage in honest self-reflection, but to respond to one's conclusions in effective and meaningful ways. Here institutions of higher learning must walk a psychosocial tightrope. On one hand we are all told to provide praise and positive feedback to build self-esteem, but on the other we know that a distorted sense of self-competence can lead to personal and professional disaster. And as with many of the dynamics discussed here, the implications of failure in this area are often even more dire for students from households limited in economic and academic resources. These students often have safety nets with large holes, and cannot afford too many deviations from their paths.

Perspicacity and the realistic appraisal of strengths and weaknesses have been noted attributes of resilient students (Morales, 2008; Tough, 2012). These abilities are closely related to Goleman's (1995) notion of "emotional intelligence," where success is often more contingent on an individual's ability to effectively manage one's view of oneself as well as one's emotions, rather than traditional measures of intelligence. These abilities, as well as the need for a degree of psychological maturity to successfully engage in metacognitive thinking and honest self-reflection, are key. These are skills and attributes important for anyone, but particularly valuable for potentially resilient students.

One of the most common phenomena reported by the students in the study was the unexpectedly intimidating nature of their initial exposure to college students from more affluent suburban schools who appeared to have been well-versed in academic culture and possessed vast amounts of academic background knowledge. See Gofen, (2009) for a discussion of cultural capital and the social value of this type of knowledge. When students are faced with this reality, it is those who are able to accept this disparity and address it that are most successful. The following quote from Jasmine, a scholarship awardee just beginning her college career at a prestigious institution, describes what many of the students reported. Here she is discussing how she felt on the first day of her European History class:

....the teacher was asking questions like what were the causes of World War I? And how did the war affect the economy?..I had no idea...I didn't even know who fought in that war....But other people knew this stuff. I got really heated (angry) I blamed the teacher, thinking the questions were stupid. I even skipped the next class as like a protest... but I couldn't keep fooling myself. After I got my first few grades back I knew that I was going to have to change my approach... Once I accepted that this was a new level and that the same old effort and systems wouldn't 
work, things started to change. I committed to reading everything I could, asking lots of questions, and going for extra help at the writing lab...these were things I never had to do before, but it was a new level.

What would have happened had Jasmine not had the humility, courage and willingness to realistically assess the situation? Had she continued to blame the professors, rather than admit she was behind and would have to change, it is unlikely she would have succeeded and maintained the necessary GPA. For students like Jasmine in situations like this, there is little room for delusion or self-pity.

Faculty must help students acquire a realistic understanding of where they are visa vie the content and skills of the particular course, and if relevant, what is required for related career paths.

Many of the suggestions below dove tail with those above regarding facilitating self-efficacy. As Tough (2012) indicates, those who are resilient not only learn from their mistakes or failings, but then act to address them.

- Professors who gave ungraded pretests and had individual, private conferences to discuss results, often helped students uncover areas for improvement without the stress and emotions tied to grades and evaluation.

This approach worked best if done earlier in the semester, giving students time to address their issues.

- Some professors, usually in education courses, took time to discuss the students' previous schooling experiences- specifically the quality and rigor of their precollege education.

This helped the students reflect on what they may have missed out on without feeling as if they should be blamed for it. Initially, students often do not realize how lacking their precollege educations may have been, but through thoughtful conversation come to realize what they have missed out on, and more importantly the extent to which their prior schooling may have been deficient.

- Several students in the study talked about faculty members and/or counselors who worked with them to jointly identify skills/attributes/competencies that students would need to acquire/work on in order to be successful and meet their academic and professional goals.

Many of the students remarked that this was the first time they ever, even informally, reflected explicitly on what they needed to do. Diana's description of an experience doing a similar exercise illustrates the potential merit of this type of self-appraisal, "Nobody ever told me what I needed to do to get ahead, like not specifically. I mean, people always tell you 'work hard' and stuff, but nobody pointed to what I needed to do and change, like stuff I needed to get better at."

Perhaps the most slippery of slopes come in helping students decide on a career or graduate school trajectory. Because first generation college students receive less guidance from home and take longer to earn their desired degrees (McCarron \& Inkelas, 2006) the role of the faculty member is especially crucial. However, often professors fear being perceived of as "dream killers," so they may tacitly encourage students to pursue goals that are unrealistic and/or wastes of time and money. Obviously, we do want to encourage students, but what the students in the study found most useful were honest and frank discussions regarding how difficult something was and whether or not success was a realistic possibility. Remembering that often these students come from households that possess little knowledge of graduate education and the white collar job market, faculty and advisors have a special obligation to provide accurate and honest assessments.

One student in the study wanted to be a lawyer simply because he "liked the way it sounded." He had a good but not great GPA, and disliked reading. A blunt and honest conversation with a criminal justice professor not only dissuaded him from that path, but opened up other career possibilities in the field that were more suited to the student's abilities and interests. According to this student, had this conversation not taken place, he would have probably spent a great deal of time and money failing out of law school.

\section{Encourage Help Seeking Tendencies}

As presented earlier, resilience theory operates under a risk/protective factor model. Protective factors mitigate the potentially negative effects of risk factors. Here the role of colleges and universities is clear, promote/encourage help seeking tendencies where potentially resilient students take advantage of available resources (protective factors). In other words, encourage help-seeking tendencies.

In addition to assisting with academic progress, utilizing available assistance facilitates two well-known components of retention, academic and social integration in the college community (Kraemer, 1997; Nora \& Rendon, 1996; Pascarella\& Terenzini, 1991; Terenzini, \& Pascarella, 1977). However, low socioeconomic students in particular are 
often less likely to be engaged in outside class activities, such as study groups, and informal interactions with faculty (Engle \& Tinto, 2008). Thus, once again facilitating these linkages is especially significant.

In terms of invaluable environmental protective factors students took advantage of, $90 \%$ of the students in the study identified college-bridge/ scholarship programs, $72 \%$ caring college personnel, and $66 \%$ college sponsored tutoring initiatives. Given the amount and severity of risk factors with which many students have had to contend, students need these resources, thus encouraging more students to seek out and take advantage of available assistance is key. Below are some ways faculty can accomplish this.

- Writing centers/labs were of particular valuable for resilient students.

Instead of waiting for students to struggle and suggesting or hoping they make an appointment, some faculty required students to take at least one paper to the writing lab before submitting it. Not only did this help improve student writing, but it made certain students knew where and how tutoring appointments took place. Many students only went to tutoring initially because they had to, but then made it part of their weekly or monthly routine. Faculty members who do not want to require it, could make a visit to the writing center worth extra points. Either way, getting students there initially often made a significant difference.

- Other faculty created assignments or activities that required students to attend university events and/or interact with available resources.

Examples included: having to attend lectures then writing response papers; scavenger hunts, where they had to get signatures from a variety of university offices; and mandatory attendance at library orientations. Additionally, some faculty invited individuals from various college offices to do brief presentation in their classes, explaining what services were available and how to take advantage of them. All of these activities exposed students to available resources, resources students often heavily relied upon at later dates. Continuous integration of resources can eventually engender and encourage help seeking tendencies and the procurement of invaluable protective factors.

- Perhaps the most direct means of getting students to take advantage of resources came from faculty who continually offered themselves up as resources.

Students reported greater "use" of professors who said things like, "Make sure to visit me during office hours," "If you do really well in this class I can write you a letter of recommendation," and "Remember, you pay the tuition, so it is our job to serve you." These simple, yet important offerings often surprised students and gave them the encouragement they needed to actually seek out assistance. One student said, "I always looked at professors as above me, as people who didn't want to be bothered by questions and stuff. But Dr. (Perez) told us to see him, even joked that he was lonely....it made it a lot easier, he was more approachable" (Lupe).

- Finally, some faculty were more proactive and explicit in their desire to connect students with resources, and took the initiative to actively connect students to people or programs from which they could benefit.

Students reported professors who suggested specific scholarships, introduced them to academic support personnel, nominated them for awards, and even set up internships. Students benefited a great deal from this sort of active mentoring and guidance.

\section{Provide Clear Linkages between Academic Success and Future Economic Security}

An essential, yet often overlooked aspect of the resilience process is the power of the presence of clear linkages between academic success (graduation) and economic security. This ties in closely with the earlier discussion on self-efficacy in that people are more likely to exert effort the more they believe that effort will indeed payoff. For potentially resilient students from poor, economically unstable backgrounds, the "payoff" is both literal and figurative.

Perhaps unlike many from middleclass and wealthier backgrounds, most resilient students view college not as a means to "enlightenment" nor becoming rich, but rather as a means to a modicum of financial security. Consequently, clear paths from graduation to career seemed to be of great motivational value. As a young woman who wanted to be an elementary teacher put it, "it was really only when I did my first practicum experience that I started to believe I could actually make a decent living teaching. That is when I started working harder. It was like I could finally see the end, there it was, only a year or two away and I could be that teacher in the front of the class." (Jessica)

Given an ever shifting and often daunting national employment picture, creating this connection between academic success and economic security can be a challenge. Additionally, many faculty may not think it is their job to do so, believing that is up to the career services offices. However, what is clear is that, regardless of where it came from, 
the connection between academic performance and economic security proved to be an essential ingredient for resilience.

Below are some of the ways colleges and faculty have managed to create or at least strengthen this connection.

- Faculty who brought the work world into their classrooms made future employment a more realistic and tangible entity.

They did this in a number of ways, including: bringing in speakers from career fields related to their academic discipline; creating assignments where students had to explore concepts inherent to prospective careers; facilitating and/or promoting available internships, employment opportunities, and graduate assistantships; and pointing out the value or early and constant resume building. All of these activities helped strengthen the connection between school and the students' futures.

\section{Conclusion}

Institutions and faculty seriously committed to improving how well they educate students from low socioeconomic and ethnic minority backgrounds must recognize that, while they are more similar than they are different, not all students are the same. Those from marginalized backgrounds often come from very different circumstances, and these circumstances significantly color both how they view themselves and their college educations. Consequently, an effective faculty member must often serve as the "cultural glue" that connects the students' precollege experiences, values and norms with those of higher education and academia.

The faculty members who proved invaluable to the success of the resilient students studied were often highly attuned to their specific needs and modified their practices to better educate them. Studying and learning about what works is an essential first step for other faculty who want to move in that same direction.

It is unrealistic to expect all faculty to engage in all of the practices outlined above. What can be enacted depends on the academic discipline, the level of the students (freshmen, sophomore, etc.), the personality and expertise of the faculty member, and the mission of the institution. However, if a majority of faculty at a given institution operate in ways that promote and facilitate the resilience tenets described, then the overall climate and culture of the institution will foster greater success for the students who are often the most vulnerable and least likely to succeed.

A significant benefit is that the modifications discussed above are not heavily resource consuming. Shifts in attitudes, assignments, and emphasis can be achieved with little time and financial expenditures- utilizing structures, routines, and processes already in place. Most faculty are interested in adapting how they teach and learning about ways they may be more effective. There are few potentially worthwhile retention initiatives that can be enacted simply by sharing ideas or engaging in a brief series of professional development workshops.

It is also helpful to emphasize the practical and "bottom line" benefits of these types of initiatives. Given budgetary constraints, the increasing questioning of the ultimate value of a college degree, and increasing public scrutiny over college tuition and graduation rates, institutions of higher learning must retain and graduate as many students as possible. Not only is it clearly good for the students and their futures, but it can improve public perception significantly.

Finally, these approaches can be considered highly inclusive and beneficial to various types of students. It is logical to assume that an institution that demonstrates an ongoing commitment to fostering resilience will end up further facilitating the success of all of its students, not just those from marginalized and disadvantaged backgrounds.

\section{References}

Astin, A. (1993). What matters in college. San Francisco: Jossey Bass.

Bai, H., \& Pan, W. (2010). A multilevel approach to assessing the interaction effects on college student retention. Journal of College Student Retention, 11 (2), 287-301. http://dx.doi.org/10.2190/CS.11.2.g

Bandura, A. (1977). Self-efficacy: Toward a unifying theory of behavioral change. Psychological Review, 84 (2), 191-215.http://dx.doi.org/10.1037/0033-295X.84.2.191

Bastedo, M.N., \& Gumport. P.J. (2003). Access to what? Mission differentiation and academic stratification in U.S. public higher education. Higher Education, 46, 341-59.http://dx.doi.org/10.1023/A:1025374011204

Bogdan, R., \& Biklen, S. (1982). Qualitative research for education: An introduction to theory and methods. Boston: Allyn and Bacon.

Conchas, G. (2006). The color of success: Race and high achieving urban youth.New York: Teachers College Press. 
Cross, K.P. (1971). Beyond the open door: New students to higher education. San Francisco:Jossey-Bass.

Dweck, C. (2006). Mindset: The new psychology of success. New York: Ballantine Books.

Ely, M. (1991). Doing qualitative research: Circles within circles. New York: The Falmer Press.

Engle, J., \& Tinto, V. (2008). Moving beyond access: College for low-income, first-generation students. Washington, DC: The Pell Institute.

Erisman, W., \& Looney, S. (2007). Opening the door to the American dream: Increasing higher education access and success for immigrants. Washington, DC: The Institute for Higher Education Policy.

Fox, M.A., Connolly, B.A., \& Snyder, T.D. (2005). Youth indicators 2005: Trends in the well-being of American youth. Washington, D.C: U.S. Department of Education.

Garmenzy, N. (1991). Resiliency and vulnerability to adverse developmental outcomes associated with poverty. American Behavioral Scientist 34 (4), 416-430.http://dx.doi.org/10.1177/0002764291034004003

Gerardi, S. (1990). Academic Self-Concept as a predictor of academic success among minority and low-socioeconomic status students. Journal of College Student Development, 31, 400-417.

Glaser, B., \& Strauss, A. (1965). The Discovery of substantive theory: A Basic strategy underlying qualitative research. American Behavioral Scientist, 8(6), 5-12.http://dx.doi.org/10.1177/000276426500800602

Gofen, A. (2009). Family capital: How first-generation higher education students break theintergenerational cycle. Family Relations, 58, 104-20.http://dx.doi.org/10.1111/j.1741-3729.2008.00538.x

Goleman, D. (1995). Emotional intelligence. New York: Bantam Books.

Hartley, M. T. (2013). Investigating the relationship of resilience to academic persistence in college students with mental health issues. Rehabilitation Counseling Bulletin, 56 (4), 240-250. http://dx.doi.org/10.1177/0034355213480527

Hawkins, R., \& Mulkey, L.M. (2005). Athletic investment and academic resilience in a national sample of African American females and males in the middle grades. Education and Urban Society, 38(1), 62-88.http://dx.doi.org/10.1177/0013124505280025

Hausmann, L., Schofield, J., \& Woods, R. (2007). Sense of belonging as a predictor ofintentions to persist among African American and White first-year college students.Research in Higher Education,48, 803-39.http://dx.doi.org/10.1007/s11162-007-9052-9

Hill, W., \& Woodward, L. (2013). Examining the impact learning communities have on college of education students on an urban campus. Journal of College Student Development, 54 (6), 643-648.http://dx.doi.org/10.1353/csd.2013.0085

Hussar, W.J., \& Bailey, T.M. (2014). Projections of education statistics to 2022. Washington, D.C: National Center for Education Statistics.

Jehangir, R.R. (2010). Higher education and first-generation students: Cultivating community,voice, and place for the new majority. New York, NY: Palgrave Macmillan.http://dx.doi.org/10.1057/9780230114678

Kitano, M. K., \& Lewis, R. B. (2005). Resilience and coping: Implications for gifted children and youth at risk. TheRoeper Review, 27(4), 200-215.http://dx.doi.org/10.1080/02783190509554319

Kraemer, B.A. (1997). The academic and social integration of Hispanic students into college: The Review of Higher Education, 20 (2), 163-179. http://dx.doi.org/10.1353/rhe.1996.0011

Lincoln, Y., \& Guba, E. (1985). Naturalistic inquiry. Beverly Hills, CA: Sage.

McCarron, G.P., \&Inkelas. K.K. (2006). The gap between educational aspirations andattainment for first-generation college students and the role of parental involvement.Journal of College Student Development, 47, 534549.http://dx.doi.org/10.1353/csd.2006.0059

McCubbin, L. (2001). Challenges to the definition of resilience. Paper presented at the meeting of the American Psychological Association, San Francisco, CA.

Morales, E.E. (2008). A focus on hope: Toward a more comprehensive theory of academic resiliency among at-risk minority students. Journal of At-risk Issues, 14 (1), 23-32. 
Morales, E.E. (2010). Linking strengths: Identifying and exploring protective factor clusters in academically resilient low socioeconomic urban students of color. The Roeper Review, 32 (3), 164175.http://dx.doi.org/10.1080/02783193.2010.485302

Morales, EE. (2012). Navigating new worlds: A Real-time look at how successful and non-successful first-generation college students negotiate their first semesters. International Journal of Higher Education, 1 , 1-23.http://dx.doi.org/10.5430/ijhe.v1n1p90

Morales, E.E., \& Trotman, F.K. (2004). Promoting academic resilience in multicultural America: Factors affecting student success. New York: Peter Lang.

Morales, E.E., \& Trotman, F.K. (2011). A focus on hope: 50 resilient students speak. Lanham, MD: RowmanLittlefield/University Press of America Press.

NCES. (2013). The Condition of education 2013. Washington, DC: National Center for Education Statistics, U.S. Dept. of Education.

Nora, A. \& Rendon, L. (1996). Hispanic student retention in community college: Reconciling access with outcomes. In C. Turner, M. Garcia, A. Nora, and I. Rendon, (Eds.), Racial and ethnic diversity in high education (pp. 269-290). Needham Heights, MA: Simon and Shuster.

O'Keeffe, P. (2013). A Sense of belonging: Improving student retention. College Student Journal, 47 (4), 605-613.

Pascarella, E.T., \& Terenzini, P. (1991). How college affects students: Findings and insights from twenty years of research. San Francisco: Jossey-Bass.

Pascarella, E.T., \& Terenzini, P. T. (2005). How college affects students (Vol. 2): A third decade of research. San Francisco: Jossey-Bass.

Pascarella, E.T., Pierson, C.T., Wolniak, G.C., \& Terenzini, P.T. (2004). First-generation college students. Journal of Higher Education, 75, 249-284.http://dx.doi.org/10.1353/jhe.2004.0016

Perna, L.W. (2005). The Benefits of higher education: Sex, racial/ethnic, and socioeconomic. Review of Higher Education, 29 (1), 23-52.http://dx.doi.org/10.1353/rhe.2005.0073

Pike, G.R., \& Kuh, G.D. (2005). First- and second-generation college students: A comparisonof their engagement and intellectual development. Journal of Higher Education, 76, 276-300.http://dx.doi.org/10.1353/jhe.2005.0021

Rotter, J. (1966). Generalized experiences for internal versus external control of reinforcement. Psychological Monograph, 80, 609-809.http://dx.doi.org/10.1037/h0092976

Rubin, H., \& Rubin, I. (1995). Qualitative interviewing: The art of hearing data. Thousand Oakes, CA: Sage Publications.

Rutter, M. (1979). Protective factors in children's responses to stress and disadvantage. In M. W. Kent \& J. E. Rolf (Eds.), Primary prevention of psychopathology: Social competence in children. Hanover, NH: University Press of New England.

Seidman, A. (2007). Minority student retention: The best of the Journal of College Student Retention. Amityville, NY: Baywood.

Terenzini, P. (1994). The transition to college: Diverse students, diverse stories. Research in Higher Education, 35 (1), 57-73.http://dx.doi.org/10.1007/BF02496662

Terenzini, P.T., \& Pascarella, E. (1977). Voluntary freshman attrition and patterns of social and academic integration in a university: A test of a conceptual model. Research in Higher Education, 6 (1), 25-43. http://dx.doi.org/10.1007/BF00992014

Tough, P. (2012). How children succeed: Grit, curiosity, and the hidden power of character.Boston: Houghton Mifflin.

Tinto, V. (1993). Leaving college: Rethinking the causes and cures of student attrition (2nd ed.). Chicago: University of Chicago Press.

Wang, M.C., \& Gordan, E.W. (1994). Educational resilience in inner city America: Challenges and prospects. Mahwah, NJ: Lawrence Erlbaum.

Werner, E. E., \& Smith, R. S. (1982). Vulnerable but invincible: A longitudinal study of resilient children and youth. New York: McGraw-Hill. 